\title{
UM GRUPO COLABORATIVO DE ESTUDOS COMO MEIO DE REFLEXÃO DA PRÓPRIA PRÁTICA DOCENTE NO CONTEXTO DA EDUCAÇÃO A DISTÂNCIA
}

\author{
LONDRINA/PR MAIO/2018
}

\author{
Renata Karoline Fernandes - Anhanguera - renata.karoline@kroton.com.br \\ Diego Fogaça Carvalho - Anhanguera - diego.fogaca@kroton.com.br \\ Mirela Ramos Moimaz Helbel - Anhanguera - mirelahelbel@bol.com.br \\ Adriana Giarola Ferraz Figueiredo - Anhanguera - adriana.gfigueiredo@kroton.com.br \\ Patrícia Beneti de Oliveira - Anhanguera - patriciabeneti@gmail.com
}

\author{
Tipo: Relato de Experiência Inovadora (EI) \\ Categoria: Conteúdos e Habilidades \\ Setor Educacional: EDUCAÇÃO SUPERIOR
}

\begin{abstract}
RESUMO
Este relato tem por objetivo apresentar as ações realizadas em um grupo de estudos, composto por professores que atuam na Educação a Distância, que se constituiu em um ambiente de aprendizagem da docência, no contexto da formação continuada, considerando a reflexão da prática de seus membros como elemento estruturante para todo esse processo. $O$ grupo visa refletir a respeito das práticas utilizadas nas aulas do curso de Licenciatura em Matemática da Universidade Anhanguera, ofertado na modalidade de Educação a Distância, a fim de elaborar, refinar e disseminar as práticas avaliadas entre os membros como boas, visando corroborar com o processo de ensino e de aprendizagem dos alunos, bem como com o desenvolvimento profissional dos docentes. Considera-se que a realização do grupo tem contribuído para a formação individual e coletiva dos professores envolvidos, propiciando que reflitam sobre sua ação docente, bem como a respeito das ações dos demais professores, embasando-se na atual literatura da área da Educação e da Educação Matemática.
\end{abstract}

Palavras-chave: Educação Matemática; Refexão da Prática; Grupo Colaborativo.

\section{AGRADECIMENTOS}

AGRADECEMOS À EQUIPE DE PROFESSORES DO CURSO DE LICENCIATURA EM MATEMÁTICA DA UNIVERSIDADE ANHANGUERA. 


\section{Introdução}

A profissão docente abrange um conhecimento pedagógico específico, bem como um compromisso moral e ético, pois no contexto de inúmeras mudanças trazidas pela sociedade, a responsabilidade de dividir o ensino com outros agentes sociais constituise um grande desafio.

Para Porto (2004, p. 32), "a formação é processo que produz a identidade da pessoa do professor, ampliando-se esse processo para o âmbito da valorização do corpo profissional, construída no e pelo conhecimento das experiências que realizam". Logo, a proposta de um grupo colaborativo de estudos, no qual há possibilidades de aprendizagem pessoal e novas práticas aliadas à forma de ensinar e de aprender, é meio de reflexão da profissão docente, no contexto da Educação a Distância.

Nóvoa (1992, p.19) sinaliza para a "necessidade de um equilíbrio entre as três dimensões essenciais à formação de qualquer professor: preparação acadêmica, preparação profissional e prática profissional". A proposta do grupo colaborativo é coerente com a atual necessidade de constante aprimoramento do saber-fazer docente, é o momento em que se efetiva uma formação continuada por meio da articulação dos saberes específicos da área de atuação do professor com os saberes pedagógicos.

Na sequência, será apresentada uma breve revisão teórica sobre o processo de reflexão da prática como meio de aprendizagem da docência, pautando-se nos conceitos de conhecer-na-ação, reflexão-na-ação e reflexão da reflexão-da-ação.

\section{A Reflexão da Prática como processo de aprendizagem da docência}

Entre meados da década de oitenta e início da década de noventa, do século passado, uma série de pesquisas no âmbito da formação de professores surgiu, trazendo em sua estrutura uma nova forma de compreender a relação entre teoria e prática. Essa abordagem ficou conhecida como o paradigma do professor reflexivo e teve como um dos seus maiores percursores o pesquisador norte americano Donald Schön que, em 1983, publicou sua primeira obra, The Reflective Practitioner. Todavia, cabe destacar que o foco dos estudos desse autor não foi diretamente a formação docente, mas a formação do profissional.

De acordo com Schön (2002, p.31), o profissional apresenta a capacidade de aprender no momento em que atua na sua prática e, para isso, vale-se do processo de conhecerna-ação, trata-se, dessa forma, "dos tipos de conhecimentos que revelamos em nossas ações inteligentes". Esse processo é caracterizado pelo autor como tácito, o que denota que nem sempre se sabe expor de forma racional as justificativas do que se faz e como 
essa prática é realizada.

Quando o processo de conhecer-na-ação não possibilita uma intervenção satisfatória, extrapolando os limites do que é considerado normalidade, o profissional é levado a iniciar um procedimento de reflexão na ação. Nesse caso, a reflexão tende a ser consciente e assume uma função crítica, na qual as estruturas dos pressupostos do processo de conhecer-na-ação são questionadas. O profissional precisa compreender quais decisões levaram-no para a situação conflituosa, problematizando a realidade. Dessa forma, a reflexão gera um experimento imediato.

[...] o que distingue a reflexão-na-ação de outras formas de reflexão é sua imediata significação para a ação. $\mathrm{Na}$ reflexão-na-ação, o repensar de algumas partes de nosso conhecer-na-ação leva a experimentos imediatos e a mais pensamentos que afetam o que fazemos - na situação em questão e talvez em outras que possamos considerar como semelhantes a ela (SCHÖN, 2000, p. 34).

Por fim, o autor apresenta um terceiro processo de reflexão da prática, que tem por objetivo complementar os demais, trata-se da reflexão sobre a reflexão-na-ação.

Após a aula, o professor pode pensar no que aconteceu, no que observou, no significado que lhe deu e na eventual adopção de outros sentidos. Reflectir sobre a reflexão-na-acção é uma acção, uma observação e uma descrição, que exige o uso de palavras (SCHÖN, 1997, p. 83).

Diante da explanação dos conceitos que estruturam a reflexão, pode-se interpretar que o processo apresentado por Schön enfoca uma formação individualizada. No entanto, por que não refletir sobre a prática individualizada em um grupo de professores? A formação em grupo possibilita a institucionalização de práticas inovadoras?

Com base nesses questionamentos e considerando os pressupostos apresentados por Ibermón (2010), é de extrema importância que, no contexto da formação continuada de professores, haja um rompimento da formação individualizada para uma formação colaborativa, visando mudanças que vão além do individual.

\footnotetext{
Podemos afirmar que a formação personalista e isolada, pode originar experiências de inovação, mas dificilmente originará uma inovação institucional e de prática coletiva dos professores. [...] A inovação institucional pretende que a inovação se estabeleça no coletivo, que faça parte de uma cultura profissional e que incorpore aos processos educacionais como um processo normal de funcionamento. Essa inovação institucional é o objetivo prioritário da formação continuada (IBERMÓN, 2010, p. 67).
}

Compreende-se que uma das formas de associar a reflexão da prática, em um contexto de formação continuada e coletiva, é organizar um grupo de estudos, promovendo uma série de práticas formativas que têm por objetivo não só a formação de cada um dos seus membros, mas a institucionalização das inovações elaboradas pelos 
participantes.Na sequência, será apresentado o objetivo do trabalho, seguido pelos procedimentos metodológicos e a discussão das atividades que são realizadas no Grupo Colaborativo do Curso de Matemática da Universidade Anhanguera.

\section{Objetivo do trabalho}

Este relato tem a intenção de apresentar a experimentação de condução e de desenvolvimento de um grupo de estudos colaborativo, formado por professores do Ensino Superior, que tem como intenção refletir a respeito de práticas, principalmente docentes, para favorecer o processo de ensino e de aprendizagem na Educação a Distância.

\section{Procedimentos Metodológicos}

Este trabalho é composto por um relato de experiência a respeito da formação de um grupo de estudos dos professores da Universidade Anhanguera, sendo predominante o caráter qualitativo, descritivo e exploratório.

De acordo com Gil (1999), a pesquisa descritiva apresenta inferência direta a respeito do objeto que está sendo analisado, no caso, o grupo de estudos, tendo a intenção de compreender e de ter maior familiaridade com os aspectos da situação em análise, buscando descrever o fenômeno de acordo com as variações de tempo.

Ainda, utilizaram-se, para a fundamentação do relato, procedimentos característicos de estudo de caso, que para Goog e Halt (1979), tem como característica a compreensão de situações que podem ou não ser generalizadas, tendo como princípio o levantamento e a organização de dados, preservando o objeto estudado.

\section{Discussão dos resultados}

O grupo de professores do curso de Licenciatura em Matemática EaD da Universidades Anhanguera, que possui seu Núcleo de Educação a Distância situado na cidade de Londrina, é composto por uma equipe eclética, que tem como componentes, além dos professores com formação em Licenciatura em Matemática, professores de Língua Portuguesa, Física, Biologia e Filosofia.

O intuito da realização do grupo de estudos, além de evidenciar a interdisciplinaridade e poder refletir a respeito de diferentes situações, é fomentar ações que possibilitem a integralização dos conceitos e das teorias em um contexto colaborativo, em que os protagonistas são os próprios docentes, que se propuseram a vivenciar uma formação continuada, em um contexto em que a reflexão da prática proporciona momentos instigantes e enriquecedores de análise, de discussão e de crescimento em conjunto, no 
tocante ao processo de ensino e de aprendizagem.

Se, conforme Bernadete Gatti, os educadores "precisam ser instrumentalizados para lidar com o ensino, que é o foco de sua profissão, e o elemento definidor de sua profissionalização" (2009, p. 100), é preciso considerar o trabalho colaborativo para promover a formação de um docente com espírito investigativo e, ainda, que consiga administrar conhecimentos teóricos e práticos de sua área, conectando-os aos conhecimentos interdisciplinares.

Nesse contexto, algumas ações têm sido desenvolvidas por esse grupo de professores, com o único objetivo de promover, entre os membros, uma formação continuada e colaborativa, a reflexão sobre a própria prática, ao analisar relatos dos demais professores, resultando na melhora da qualidade do processo de ensino e de aprendizagem.

O grupo de estudos do curso de Matemática da modalidade de Educação a Distância acontece semanalmente, no período em que os professores da Universidade Anhanguera realizam a permanência, durando, em média, 45 minutos. Como citado anteriormente, esse grupo tem a característica de se colaborativo, por esse motivo, não existe uma figura de coordenador para ele, assim, os temas a serem tratados e as atividades desenvolvidas são sugeridas por todos os membros do grupo, de acordo com o interesse ou a necessidade.

A partir desse momento, serão apresentadas algumas das atividades que foram desenvolvidas no curso, quais os objetivos delas e algumas reflexões.

Umas das ações realizadas foi a análise da Base Nacional Comum Curricular (BNCC), homologada em dezembro de 2017, momento em que foram levantadas questões pertinentes ao contexto educacional abarcado nesse documento, a Educação Infantil e o Ensino Fundamental, com vistas ao quadro apresentado no contexto da educação matemática e das demais áreas, buscando organizar orientações possíveis, a partir desse estudo, para a prática docente no Ensino Médio e no Ensino Superior (presencial e a distância). O intuito do grupo, com essa atividade, foi repensar alguns conceitos, rever algumas práticas e interagir com um documento oficial da Educação.

Considera-se que, ao final dessa atividade, os participantes discutiram a respeito das principais mudanças para a Educação Básica, visto que todos atuam no curso de Licenciatura em Matemática, ou seja, são formadores de futuros professores da Educação Básica e, ainda, puderam pensar em estratégias para aplicar em suas aulas, 
para favorecer o processo de ensino a respeito dos temas tratados na BNCC.

Com o intuito, ainda, de propiciar, de fato, colaboração e reflexão dentro do grupo, várias dinâmicas (quadro 1) foram realizadas ao longo dos encontros semanais. Um fato interessante, nessa ação, é a multiplicidade de performances, que envolvem diversas áreas do conhecimento e todas as disciplinas. A cada semana, um professor fica responsável pela dinâmica, buscando levar atividades que proporcionem reflexões no âmbito pessoal e profissional, que são articuladas na visão da coordenação, dos docentes, dos alunos e da instituição escola/universidade como um todo.

No quadro 1, apresentam-se algumas das atividades desenvolvidas, quais foram os objetivos e uma reflexão a respeito do desenvolvimento de cada uma delas.

Quadro 1 - Algumas dinâmicas realizadas durante o grupo de estudos.

\begin{tabular}{|c|c|c|}
\hline Dinâmica & Objetivo & $\begin{array}{l}\text { Reflexão a respeito do } \\
\text { desenvolvimento }\end{array}$ \\
\hline $\begin{array}{c}\text { Apresentação do vídeo - } \\
\text { Filme Avaliação Escolar } \\
\text { EMIP } \\
\text { Disponível em: } \\
\text { https://www.youtube.co } \\
\text { m/watch?v=bQWBFz7Nh } \\
\text { E0 }\end{array}$ & $\begin{array}{l}\text { Refletir sobre o processo de } \\
\text { avaliação escolar, discutindo as } \\
\text { cenas e os comentários na } \\
\text { legenda do filme. }\end{array}$ & $\begin{array}{c}\text { No momento de interação, os } \\
\text { participantes se posicionaram a } \\
\text { respeito das características } \\
\text { inerentes ao processo de } \\
\text { avaliação escolar, destacando-se } \\
\text { a análise a respeito do papel do } \\
\text { professor na Educação a } \\
\text { Distância e na mediação do } \\
\text { conhecimento; também a respeito } \\
\text { da importância da retomada de } \\
\text { conteúdos após as avaliações, } \\
\text { inserindo ao máximo elementos } \\
\text { de formação no processo de } \\
\text { avaliação e como avaliar o } \\
\text { estudante da Educação a } \\
\text { Distância. }\end{array}$ \\
\hline $\begin{array}{c}\text { Vídeo elaborado pela } \\
\text { professora responsável } \\
\text { pela dinâmica do dia - } \\
\text { encerramento do ano de } \\
2017 \text {, com momentos de } \\
\text { interação e de }\end{array}$ & $\begin{array}{c}\text { Mostrar como o trabalho é } \\
\text { efetuado na EaD, mostrando a } \\
\text { parceria existente no grupo para a } \\
\text { realização das atividades. }\end{array}$ & $\begin{array}{l}\text { Com a apresentação do vídeo- } \\
\text { resumo de algumas atividades } \\
\text { desenvolvidas ao logo do ano de } \\
\text { 2017, os professores puderam } \\
\text { analisar o desenvolvimento } \\
\text { individual e do próprio grupo, }\end{array}$ \\
\hline
\end{tabular}




\begin{tabular}{|c|c|c|}
\hline $\begin{array}{c}\text { confraternização dos } \\
\text { professores que } \\
\text { compõem o grupo } \\
\text { docente de Matemática. }\end{array}$ & & $\begin{array}{c}\text { retomando boas práticas } \\
\text { realizadas. }\end{array}$ \\
\hline Cápsula do tempo. & $\begin{array}{c}\text { Instigar e revelar os planos futuros } \\
\text { dos docentes, seus projetos e } \\
\text { objetivos a serem alcançados. }\end{array}$ & $\begin{array}{c}\text { Essa atividade foi desenvolvida } \\
\text { para estimular o planejamento dos } \\
\text { professores, permitir que os } \\
\text { participantes do grupo pudessem } \\
\text { realizar planos, expor seus } \\
\text { desejos que gostariam de realizar } \\
\text { até o ano de } 2021 . \text { Essa atividade } \\
\text { foi proposta, por se compreender } \\
\text { a importância de ter metas e foco } \\
\text { no desenvolvimento de atividades } \\
\text { profissionais e planejamento das } \\
\text { atividades que deveriam ser } \\
\text { realizadas para que os objetivos } \\
\text { sejam alcançados. }\end{array}$ \\
\hline $\begin{array}{l}\text { Quociente de } \\
\text { criatividade. }\end{array}$ & $\begin{array}{l}\text { Instigar a percepção de símbolos, } \\
\text { desenvolvendo a criatividade por } \\
\text { meio da interpretação do que se } \\
\text { encontra representado na figura. }\end{array}$ & $\begin{array}{c}\text { Após a realização da atividade, } \\
\text { considera-se que a criatividade } \\
\text { deve fazer parte do trabalho do } \\
\text { docente da Educação a Distância, } \\
\text { pois mesmo com as diferenças de } \\
\text { local e de tempo, o professor deve } \\
\text { ser capaz de mediar e de facilitar } \\
\text { o processo de ensino e de } \\
\text { aprendizagem e a criatividade. Ao } \\
\text { utilizar os diferentes instrumentos } \\
\text { possíveis, as Tecnologias de } \\
\text { comunicação, entre outros } \\
\text { elementos, podem fazer a } \\
\text { diferença nesse processo. }\end{array}$ \\
\hline Alfabeto Braille. & $\begin{array}{l}\text { Conhecer um pouco sobre o } \\
\text { alfabeto Braille, no intuito de } \\
\text { discutir sobre a educação } \\
\text { inclusiva. }\end{array}$ & $\begin{array}{c}\text { Percebeu-se, com a realização } \\
\text { dessa atividade, a necessidade de } \\
\text { que o grupo se preparasse para a } \\
\text { inclusão escolar. }\end{array}$ \\
\hline Percepção. & $\begin{array}{c}\text { Refletir sobre como o aluno da } \\
\text { EaD pode compreender as aulas, } \\
\text { dependendo de como elas são }\end{array}$ & $\begin{array}{c}\text { Com essa atividade, houve a } \\
\text { reflexão a respeito da importância } \\
\text { do detalhamento no planejamento }\end{array}$ \\
\hline
\end{tabular}




\begin{tabular}{|l|c|c|c|} 
transmitidas pelo professor, & das aulas e o modo de apresentar \\
proporcionando, para os docentes & o conteúdo, pois a forma como \\
do curso, o reconhecimento da & um mesmo conteúdo é tratado, \\
importância de uma aula bem & pode impactar, diretamente, na \\
estruturada para a compreensão & compreensão dos estudantes. \\
dos alunos, assim chegando aos & \\
resultados desejados. & \\
\hline
\end{tabular}

Fonte: os autores, 2018.

O grupo é sempre levado a refletir, a questionar, a dialogar, a contestar e a repensar todo o âmbito educacional e até pessoal. E o mais interessante, nas dinâmicas realizadas até agora, foram as intervenções dos participantes, que se propuseram a realizar tudo o que era proposto, independentemente de a proposta fazer parte do contexto particular em que cada um está inserido. Por exemplo: em uma atividade em que a proposta era construir uma imagem, a partir de conceitos matemáticos, as professoras de Biologia e de Língua Portuguesa participaram mesmo sem o conhecimento de todos os termos enumerados ao longo da dinâmica. E o resultado foi profícuo, pois todos acabaram pensando nos alunos, nas situações em que aquilo que ouvem do professor não faz sentido algum ou os leva a um caminho que não era o esperado.

Outra ação desse grupo colaborativo diz respeito às "aulas de Língua Portuguesa", uma oportunidade de acesso a conceitos, teorias, regras e particularidades que visam tornar todos os envolvidos mais proficientes no trato com a língua, o que, certamente, trará resultados positivos na prática diária de cada um, diante de uma elaboração de prova, por exemplo, ou na própria interlocução com o alunado. A cada semana, o grupo decide o tema a ser abordado no encontro seguinte, vislumbrando contextos que possam instrumentalizar cada componente para a sua prática diária.

Outra iniciativa relevante do grupo diz respeito à realização das microaulas, em que os professores simulam a abordagem de um conteúdo, sendo analisados por seus pares. Depois, os professores se reúnem e apresentam a sua visão da aula realizada, elencando os pontos positivos e negativos, seguidos de sugestão. Em suma, essa plenária tem por objetivo se configurar um ambiente de aprendizagem da docência em que o saber-fazer dos professores possa ser refinado e aprimorado por meio do processo de reflexão.

No contexto apresentado do grupo colaborativo como espaço de aprendizagem da 
docência, por meio da reflexão da prática, todas as ações realizadas, até o momento, mostraram as potencialidades iminentes que se configuram em um espaço formativo para elaboração, para análise e para utilização de teorias e de métodos educativos, quando isso se dá por meio da discussão coletiva entre professores de diferentes áreas: trata-se de uma oportunidade ímpar de crescimento, de interação e de troca, elementos fundamentais para a base de uma formação com excelência.

\section{Considerações Finais}

Este relato de experiência teve por objetivo apresentar as atividades que são realizadas, semanalmente, no grupo de estudos colaborativo, formado pelos professores da Universidade Anhanguera do curso de Matemática, ofertado na Modalidade de Educação a Distância.

Uma das principais características do grupo é a colaboração dos professores envolvidos, com a intenção de contribuir com o processo de aprendizagem dos alunos. O grupo não possui uma pessoa que assume o papel de coordenador, e as atividades são planejadas e desenvolvidas pelos próprios participantes, sempre voltadas às necessidades que emergem durante a prática.

De acordo com o relato apresentado, é possível observar que a prática docente de cada um dos membros é problematizada, assumindo a aprendizagem do aluno como critério desse processo, bem como as limitações inerentes ao contexto em que as práticas são inseridas. Consequentemente, o professor aprende a respeito da docência no contexto da EaD, baseando-se na problematização de suas práticas, bem como das práticas de seus pares.

Compreende-se existirem dois processos: o primeiro, de aprendizagem individual, ou seja, cada professor aprende de acordo com suas leituras, concepções e crenças, entre outros meios; o segundo, refere-se a uma aprendizagem coletiva, pautando-se nas normas e nos valores que são compartilhados entre os membros do grupo e a instituição a qual pertencem. Em suma, é na confluência desses dois processos que se vislumbra a aprendizagem docente.

\section{Referências:}

BRASIL. Ministério da Educação. Base Nacional Comum Curricular: educação é a base. Brasília: MEC, 2017

GATTI, Bernadete A. Formação de professores: condições e problemas atuais. Revista Brasileira de Formação de Professores, Cristalina, v. 1, n. 1, p. 90-102, maio 2009. 
GIL, A. C. Métodos e Técnicas de Pesquisa Social. Atlas. São Paulo, 1999.

GOODE W.J, HATT P. K. Métodos em pesquisa social. 5a ed. São Paulo: Companhia Editora Nacional;1979.

IMBERNÓN, F. Formação continuada de professores. Tradução de Juliana dos Santos Padilha. Porto Alegre: Artmed, 2010.

NÓVOA, A. Os professores e a sua formação. Lisboa: Dom Quixote, 1992.

PORTO, Y. da S. Formação continuada: a prática pedagógica recorrente. In: MARIN, A. J. (Org.). Educação Continuada. 2. ed. Campinas, SP: Papirus, 2004. P. 11-37.

SCHÖN, D. A. Educando o profissional reflexivo: um novo design para o ensino e a aprendizagem. Tradução de Roberto Cataldo Costa. Porto Alegre: Artes Médicas Sul, 2000.

A formação de professores: novas perspectivas baseadas na investigação sobre o pensamento do professor. In: NÓVOA, A. (Org.). Os professores e sua formação. 3. ed. Lisboa: Publicações Dom Quixote, 1997. 